\title{
VUELOS SOBRE LO NUEVO. CIENCIA FICCIÓN EN COLOMBIA 1928-1936.
}

\author{
POR \\ Juan Manuel Espinosa \\ Instituto Caro y Cuervo, Bogotá
}

ParaFredric Jameson, en un incisivo y concienzudo análisis llamado Una modernidad singular (2004), el peso de la palabra "modernidad" no recae en el hecho de que sea un período histórico que nos permita describir el presente con respecto al pasado. Tampoco es un concepto o una categoría filosófica -según él no es ni lo uno ni lo otro-. El peso de la palabra "modernidad" se encuentra en el hecho de que es una categoría narrativa (44), una figura retórica que ha regido sin obstáculo alguno en la forma de contar la historia de Occidente-y ahora del mundo entero-. Su fuerza crucial radica en que ejecuta múltiples variaciones y movimientos para marcar una ruptura con un pasado y proponer una "primera vez", y esa primera vez, esa innovación, es lo que se debe preservar. Es por ello que, al analizar detenidamente los usos de "moderno", Jameson nos revela que junto a la capacidad que tiene para periodizar el tiempo y la historia esta palabra trae consigo el imperativo de Rimbaud -que Jameson usa como título para sus conclusiones- de "Il faut être absolument moderne", hay que ser absolutamente moderno. Eso lo lleva a concluir que "[...] lo más significativo es que la modernidad de los Estados en cuestión es modernidad para otros pueblos, una ilusión óptica alimentada por la envidia y la esperanza, los sentimientos de inferioridad y la necesidad de emulación. Al lado de las restantes paradojas contenidas en este extraño concepto, esta es la más fatal: que la modernidad es siempre un concepto de la otredad" (177).

Podemos estar de acuerdo o no con su análisis de las particularidades y de los autores que lee, y podemos estar o no junto a él con respecto a la conclusión. Sin embargo, la utilidad de este enfoque radica en que podemos dejar a un lado las discusiones y las plantillas de si una nación, un movimiento literario o un artefacto cultural es o no moderno con respecto a un estándar idealizado e imposible de alcanzar. Eso nos da permiso para enfocarnos en las relaciones que esos artefactos culturales, en este caso las tres novelas que vamos a entrar a mirar, entablan con la innovación, ese elemento que la modernidad valora y convierte en el imperativo a seguir. 
Además, las novelas Una triste aventura de catorce sabios (1928), Barranquilla 2132 (1932), y Viajes interplanetarios en zepelines que tendrán lugar el año 2009 (1936), al ser parte del género de la ciencia ficción, tienen una relación con lo nuevo aún más incisiva. Darko Suvin, en su libro ya clásico sobre el género, apunta como uno de sus rasgos estructurales lo que él bautiza como novum: "La ciencia ficción se distingue gracias al dominio o hegemonía narrativa de un 'novum' ficcional (una novedad o innovación) validado por la lógica cognitiva" (63, traducción mía). ${ }^{1}$

Si bien en un primer nivel esta definición nos permite fácilmente decir que estas novelas sí pertenecen al género de la ciencia ficción, no es eso lo más importante. En vez de caer en el imperativo de ser modernos y de entrar a comparar e idealizar modernidades ajenas, o de construir una historia de la ciencia ficción colombiana independiente, pero tácitamente sumisa a la historia de la literatura colombiana "seria", los vuelos de estas novelas sobre lo nuevo nos permitirán intervenir el discurso normalizado de la historia literaria colombiana.

Utilizo esta figura del vuelo como unión conceptual de las tres novelas no sólo porque es un evento trascendental en la época en que fueron escritas, o porque es el único elemento tecnológico en común que encontramos en las tres. Más allá de la maravilla tecnológica que hace posible el desplazamiento aéreo, y el consecuente acortamiento de tiempo al recorrer distancias, el vuelo y la posibilidad de hacerlo repercuten en las economías significativas de las tres novelas. Son estas economías significativas las que permiten la intervención historiográfica.

Primero, porque al incluirlas en el repertorio de la literatura colombiana se nos revela un hecho sorprendente: la ciencia ficción colombiana no nace en la capital del país, donde se concentra el poder político e institucional del Estado. Nace en la región Caribe: José Félix Fuenmayor y Manuel Sliger Vergara son oriundos de la región (Barranquilla y Montería, respectivamente); José Antonio Osorio Lizarazo, si bien nació en Bogotá, escribe su única novela de ciencia ficción mientras vive en Barranquilla, y ubica la acción allí.

Esta aparición del género en una región particular, en un período de ocho años, nos lleva también a replantear lo dicho acerca de la conformación de la literatura del Caribe colombiano y su relación con la del resto del país. La modernidad literaria se ha dicho que llega al país a través de Barranquilla con la revista Voces (José Félix Fuenmayor y Ramón Vinyes hacían parte de la publicación) y luego esto se sostiene durante los cuarenta y cincuenta con el Grupo de Barranquilla. Sin embargo, estas tres novelas demuestran que el ingreso de la modernidad literaria de alta alcurnia esconde también una confrontación con lo nuevo que ha pasado desapercibida.

El concepto es derivado de la obra de Ernst Bloch, para quien el novum se refiere a innovaciones concretas en la historia que despiertan la conciencia colectiva humana de un presente estático, para hacerles pensar que la historia puede cambiar (Csicsery-Ronay 119). 
Lo mismo se puede decir para el rezago historiográfico de la literatura del período de La Violencia, y para la ubicación del género del realismo mágico, y de García Márquez, en el centro del sistema literario colombiano. ${ }^{2}$

Estas novelas de ciencia ficción se alejan tanto de la violencia partidista como de los tropos folclorizantes del realismo mágico, no porque sean libros escapistas, sino por el simple hecho de que fueron escritos antes de la aparición de ambas categorías historiográficas, lo que nos permite ver intereses, ángulos y panorámicas distintas a las que han sido hegemónicas.

Por último, estos vuelos sobre lo nuevo no sólo permiten ver más allá de categorías literarias tradicionales, sino que incluso nos fuerzan a tener en cuenta aspectos que no se tienden a tener en cuenta en los estudios literarios colombianos, en específico, el lugar que la tecnología tiene en la cultura colombiana (Osorio), el humor como mecanismo igualizante en una sociedad profundamente clasista (Fuenmayor), y la relevancia de lo visual sobre lo escrito y las consecuencias que la atención a lo visual puede tener en relación con el poder del letrado, figura paradigmática de la cultura colombiana (Sliger).

1. Barranquilla 2132 cuenta la historia de Juan Francisco Rogers, un médico en la Barranquilla de 1940, que logra criogenizar animales y luego despertarlos. Decide ser su propio sujeto de estudio y entrar en suspensión animada, así que se esconde en el sótano de un edificio donde permanece hasta 2132, cuando una bomba destruye la construcción y permite que sea descubierto. A través de múltiples diálogos entre Rogers y los periodistas que cubren la noticia de su aparición, se revela cómo era el antiguo mundo y cómo es el nuevo, sólo retomando en el último tercio de la novela el asunto de la bomba. Rogers y uno de los periodistas descubren que el causante de esas bombas es un científico genio, que viaja solo en su dirigible bombardeando ciudades importantes con el fin de acabar con el orden mundial y proclamarse gobernante supremo. Sin importar cuán atribulado esté Rogers, un claro héroe trágico y sensible, la novela cumple con las prerrogativas del género de aventuras: Rogers y el periodista logran vencer al científico malvado y volver a Barranquilla. Sin embargo, la alienación que sufre Rogers, un personaje marcadamente dostoievskiano, es tal que luego de volver a tierra decide no ser parte de ese nuevo mundo, ahogándose por voluntad propia en las aguas del río Magdalena.

Esta alienación comienza tan pronto Rogers despierta y percibe los grandes cambios que han ocurrido. Una gran catástrofe alrededor del año 2000 había acabado con la civilización tal como él la conocía para ser remplazada por otra donde la eficiencia, la

2 El caso paradigmático de esta organización conceptual e historiográfica es el libro de Seymour Menton, Planetas y satélites. Si el sistema literario es equiparado al sistema solar, el Sol obviamente es García Márquez. 
rapidez y la sencillez eran los ideales a seguir. Esto ocurre a niveles tecnológicos -la impresión y distribución de periódicos, por ejemplo, que se hace por medio de tubos de vacío que recorren la ciudad, o el paso del uso del automóvil a la avioneta como medio individual de transporte. Pero más importante para Rogers y para la novela, estos cambios se encuentran arraigados en los terrenos culturales y sociales.

Este relato es una excusa perfecta para Osorio para hablar de lo nuevo, pero no con el énfasis en lo nuevo como portador de esperanzas y mejores futuros, típico de la ciencia ficción pulp norteamericana de Hugo Gernsback en Amazing Stories, sino con una clara tribulación: junto con las novedades tecnológicas o sociales llegan también imágenes que no sólo muestran futuros esperanzadores, sino miedos y amenazas de que la historia continúe tal y como venía continuando para el momento en que se escribe el relato.

Todo se ha simplificado en el nuevo mundo de Rogers. Los antiguos nombres como "Gutiérrez" han sido abreviados a "Gu", y el saludo y la presentación con un apretón de manos se han convertido en objetos de burla pues con ellos se pierde energía y no se gana eficiencia. La ciudad entera yace en silencio a cualquier hora del día, y el español hablado ha perdido sus particularidades regionales manifestando una "[...] universalización del lenguaje, impuesta por la aproximación de todos los pueblos", un efecto benéfico de la eficiencia (23). La vestimenta ha perdido todo adorno y sin diferenciar géneros, buscando la sencillez, la comodidad y la ligereza. Esta sencillez ha dado paso a la uniformidad a todos los niveles sociales y culturales.

La alienación de Rogers no se debe explícitamente a cambios generales en la civilización, sino a dos prohibiciones o tabúes sociales específicos a los que él vuelve una y otra vez. Son ellos los que nos permiten entrever el miedo soterrado a las posibilidades de lo nuevo. Esto lo veremos a dos niveles en esta novela, en el nivel político, y en el nivel estético. Ambos, sin embargo, están conectados precisamente por medio de estas dos nuevas prohibiciones.

En un pasaje clave respecto a los dos tabúes - comer en público y mirar el cuerpo femenino-el narrador sintetiza lo que se ha ganado y perdido: "El sentimiento admirativo era delincuencia, como era repugnante y de mal gusto comer en público. La mujer no era lo que antes. Se inventaron nuevos aparatos mecánicos como cooperadores de la vida humana, se concedía al confort y a la facilidad en los transportes una importancia primordial" (48). Por ello los restaurantes han desaparecido y junto a ellos las reuniones para comer en grupo, y el individuo ha remplazado a la mujer como el anhelo de belleza (49). Esto, para Rogers, es el símbolo de una nueva sociedad ya del todo perdida:

Pero el espíritu, la concepción de los principios fundamentales, la moral, la metafísica, las ciencias especulativas habían sufrido una alteración que no era proporcional al progreso físico. La ascensión, en este sentido, no había observado leyes de ninguna especie y, en cierto sentido, la vida que ahora empezaba a descubrirse la antojaba primitiva, absurda como un retorno. (48) 
La materia, la tecnología, la innovación mecánica e industrial, todo eso no le importa tanto a Rogers como la preservación del espíritu, esos principios fundamentales que según él yacen bajo la actitud gregaria a la comida y en la admiración del cuerpo de la mujer. En un primer momento parece bastante catastrófico - e incluso traído de los cabellos- pasar de la costumbre de no comer en público o de mirar a una mujer en la calle, a decir que la civilización se ha tornado primitiva y absurda. Pero el peso de estas dos costumbres perdidas no son para él un simple cambio hacia una nueva etapa de desarrollo social. Estos son sólo síntomas de la desaparición del espíritu, y de todo lo que se desprende de ese concepto: la religión, el amor, el arte, y la admiración estética del mundo como tal (encarnado siempre en el cuerpo femenino y en un segundo plano, la naturaleza):

[...] jamás había escuchado una simple expresión metafísica, ni alusiones al espiritualismo, ni al más allá, ni religión alguna. No parecián existir templos dentro de las nuevas instituciones. El arte se había rebajado a suprimir de su interpretación toda tendencia puramente contemplativa. El amor era ahora el más trivial de los contratos, la más vulgar de las amistades: y como consecuencia de ella, la capacidad admirativa había desaparecido: nada producía sorpresa, nada despertaba un verdadero interés, dominaba una apatía desconsoladora por todo lo que no fuera el más brutal de los egoísmos. (77)

El peligro yace en la pérdida de lo espiritual. Es la ausencia de valores lo que degrada y deprime el mundo. La distopía en el nuevo mundo que presenta Osorio no se debe a realidades políticas totalitarias o a rearticulaciones de la tecnología en la sociedad de consumo. En ese sentido esta novela sobre un mundo nuevo con su correspondiente lado oscuro se aleja de las convenciones de la entonces naciente novela distópica (Nosotros de Evgueni Zamiatin [1922], Un mundo feliz de Aldous Huxley [1931] y 1984 de George Orwell [1949]). Es la constelación de ideas machistas, de congregación alrededor de una mesa, y de preconcepciones esencialistas del arte, cada una con un cariz melancólico y todas con un común denominador -la espiritualidad desaparecida- lo que revela el peligro que acecha en la nueva sociedad.

"Reconocía que bajo algunos aspectos la vida se había simplificado profundamente", nos dice Rogers. "Pero a cambio de cuánta espiritualidad, cuánto vigor mental, cuánto regocijo corporal se había eliminado!" Las satisfacciones se han dejado a un lado quitándole así "toda seducción de la existencia" (74). Han desaparecido los placeres epicúreos y ha sido modificado el amor: “[...] no existía ya la posibilidad de las arcaicas emociones de los primeros besos, las primeras frases de dulce nombre, del cine de todas las novelas románticas de su época. Ahora era un contrato severo, adusto, en que nadie renunciaba a su independencia ni contraía responsabilidades". Y al hablar de deberes comunales se pasa de inmediato a la queja de no poder "[...] admirar la maravilla de un contorno femenino que ondulaba por la calle". La objetificación de la mujer pasa 
sin transición alguna al juicio estético y artístico: “[...] el arte [de esa nueva época] era angular, áspero, arte de motor y de geometría. Nada restaba de los ideales culturales de otros siglos, cuando se concretaba la máxima expresión estética en el desnudo femenino, que era ahora bestial y estúpido" (74). La modernización de instituciones y de sociedades no puede existir, podemos concluir, sin la pérdida de los ideales estéticos y sensuales encarnados en el cuerpo de la mujer y en la cena en grupo.

Es esta antinomia lo que no nos permite pensar que la amenaza de una pérdida espiritual se deba a una raigambre explícitamente católica en la novela. Si bien hay una fuerte ideología religiosa detrás, no hay una conexión con la institución eclesiástica como tal.

Para cuando Osorio llega a Barranquilla, acababa de comenzar la República Liberal (1930-1946), período en el cual el Partido Liberal llega al poder en Colombia luego de cuarenta y cuatro años de gobierno de un Partido Conservador centralista y de fuerte catolicismo ultramontano. Es esta conexión política lo que lo lleva a trasladarse de Bogotá a Barranquilla, para trabajar en el periódico El Heraldo, recientemente fundado por el Partido Liberal en la costa atlántica del país con el propósito de contrarrestar la hegemonía de los periódicos bogotanos.

Nacido en 1900 en Bogotá, Osorio de seguro vivió un shock cultural al llegar al Caribe precisamente cuando la República Liberal comenzaba a pensar cuáles eran sus proyectos y metas para la nación. Sin haber salido antes de la zona andina y sin que a Bogotá hubieran empezado a llegar las inmigraciones internas que caracterizarían el cambio demográfico de la segunda mitad del siglo XX, la Costa-como se le conoce en Colombia a la región Caribe-, el costeño, y en especial Barranquilla, eran lo más distante y distinta a la Bogotá del momento. No sólo en cuestión de diferencias sociales y culturales entre la región andina y la caribe, sino también con respecto a una clara diferencia en el nivel del desarrollo urbano, tecnológico, industrial y comercial de la ciudad costeña. La llegada del primer avión y el primer aeropuerto en 1919 a Barranquilla -y no a la capital-, edificios de cinco o más pisos, la mayoría de las calles asfaltadas, y la gran presencia de extranjeros, eran realidades desconocidas en la Bogotá de la época. De ahí que la mención en la novela, por ejemplo, de la informalidad a la hora de saludar y de presentarse no sólo sea un rasgo diferenciador entre colombianos y extranjeros, sino también entre bogotanos y barranquilleros. Esta enajenación cultural entre regiones se exacerba en el caso de Osorio, debido a su particular entendimiento de lo político, y del lugar del Partido Liberal en la política, conectada con la posición hegemónica de la espiritualidad como núcleo de la tradición, civilización y belleza. ${ }^{3}$

Entiendo la diferencia de "lo político" y "la política" de acuerdo a lo sugerido por Chantal Mouffe: "concibo 'lo político' como la dimensión de antagonismo que considero constitutiva de las sociedades humanas, mientras que entiendo 'la política' como el conjunto de prácticas e instituciones a través 
Tal y como lo muestra Calvo Isaza, Osorio estaba cercanamente afiliado con las directrices del Partido Liberal colombiano. Si bien tenía una conciencia social y una preocupación por los problemas de las diferentes clases sociales en Colombia, tal y como se puede ver en sus novelas posteriores (en especial El día del odio [1953]), no parece confiar en las capacidades políticas del pueblo. Esto se debe a que no considera el antagonismo constituyente de una sociedad como un mecanismo efectivo de cambio social. No hay antagonismo porque el pueblo no puede ni debe encargarse del manejo de la nación y del Estado. Al igual que el proyecto liberal colombiano -en ese entonces como hoy en día- asumía que era necesaria una élite que desde arriba contribuyera a la construcción de una sociedad más justa, sin permitirse concebir los procesos antagónicos como la dimensión donde esa sociedad más justa en efecto se pueda construir.

Es por ello que la amenaza tácita que recorre este relato distópico no es la misma que vemos en las novelas como la de Zamiátin, Huxley u Orwell. Cuando Osorio percibe la amenaza de la espiritualidad ausente no es debido a una amenaza comunista, si la entendemos como en la producción de ciencia ficción norteamericana de la Guerra Fría - la obra de Robert A. Heinlein en particular- embebida del "pánico rojo" a una posible pérdida de la autonomía. No hay mención alguna de autonomía o de destino en la novela. Osorio tampoco percibe un peligro en la diseminación del capitalismo a través de los esfuerzos de Norte América, que llevaba ya varias décadas presente en el Caribe colombiano para cuando escribe la novela. ${ }^{4}$

Alo que más atención se le dedica es a las relaciones problemáticas entre instituciones, líderes, y pueblo. Es a través de las explicaciones que los periodistas le dan a Rogers de cómo llegó el mundo a ser lo que es, donde podemos percibir con claridad los miedos de Osorio y la única posible solución que encuentra a esta nueva situación: En la Barranquilla de 1932 se imagina un futuro en el que se deberá rescatar el modelo de Estado Liberal, no de las garras de un comunismo que arranca la autonomía y la libertad de los individuos, sino de las secuelas de un comunismo que con la mecanización e industrialización ciega aniquilará la espiritualidad.

La razón por la cual Osorio apunta a este miedo, y a este modelo político como su posible solución, es que una estructura católica subyacente persiste en su visión de mundo, a nivel estético, ontológico y político, al igual que en la de sus copartidarios

de las cuales se crea un determinado orden, organizando la coexistencia humana en el contexto de la conflictividad derivada de lo político" (16).

4 En ese nuevo mundo unificado después de la catástrofe, las naciones y los nacionalismos han desaparecido. Una asociación internacional entre ciudades del mundo, cuya idea originaria pareciera ser la Liga de Naciones (1919-1946), es el órgano institucional supremo. Un mundo conectado por rutas comerciales y medios de comunicación, tan parecido al actual, podríamos hablar del retrato de un mundo globalizado, si no fuera por el hecho de que esa palabra sólo comenzó a ser utilizada a principios de los años setenta (véase Scheuerman). Pero si bien esto podría parecer lo más relevante a los lectores hoy en día, poco más se dice de ello en la novela. 
(si bien en el día a día los liberales se alejaban de cualquier relación con la Iglesia). Para ellos hay un imperativo de raigambre católica: el de buscar por cualquier medio la armonía y la conciliación -el catolicismo en su sentido original- no sólo al nivel de lo político o de la política, sino también a un nivel intelectual y cultural. En otras palabras, más allá de las ideas liberales o democráticas y más allá del proyecto liberal de un Estado más eficiente, eficaz y productivo, el ideal de sociedad y de Estado para Osorio se acerca bastante al de la Ciudad de Dios agustiniana, caracterizada por una ausencia total y eterna de conflicto.

Es precisamente esta tácita utopía católica en Osorio lo que le hace desconfiar del modelo comunista en la vida real, y lo que hace a Rogers desconfiar de ese nuevo mundo. Es la ausencia de espiritualidad en las máquinas y en la tecnología lo que le repele del modelo político porque sólo con espiritualidad se puede llegar al modelo conciliatorio. ${ }^{5}$ Según el relato de los periodistas, el cataclismo de la civilización ocurrido en el año 2000 se debió a la introducción de las máquinas a niveles masivos, principalmente en los países comunistas. Estas máquinas remplazan a los humanos en el trabajo, lo que con el tiempo produce -sin que quede claro cómo- una hambruna de proporciones mundiales. El pueblo entra en guerra contra los Estados debido al hambre (44), y en consecuencia los Estados no sobreviven intactos, pues se transforman en algo mucho más eficiente, en buena medida debido a la disminución demográfica mundial. Estas nuevas instituciones heredan la eficiencia y la rapidez de las imágenes utópicas de la tecnología típicas desde mediados del siglo XVIII. Como bien dicen los periodistas de 2132 cuando hablan de la impresión que se llevan de las instituciones políticas del siglo $\mathrm{XX}$, de acuerdo a los pocos documentos que sobrevivieron, "[las instituciones] dejan un margen de indecisión, de torpeza, de titubeo" (69).

Es por ello que el comunismo no es criticado por ser un régimen contrario a la democracia, sino por el uso irreflexivo de las máquinas. Pero es esta automatización lo que produjo el nuevo mundo, un mundo que no es del todo democrático, al menos como lo explica Rogers. Al describirle el régimen democrático a los periodistas, se nos permite ver el diagnóstico de la situación social y política de la Colombia de los años treinta según Osorio:

La política se agitaba en círculos y en sanhedrines adonde no llegaba el ojo del pueblo. Había clases directoras, de cuyo seno salían los usufructuadores de los cargos de elección, los administradores del erario, los gobernantes y los ministros. En realidad, ahora puedo hablar con libertad sobre la gran farsa de la democracia. En mi tiempo me hubieran injuriado los mismos hijos del pueblo sometidos a la servidumbre moral

5 Tal y como lo expone claramente Calvo Isaza al examinar el nacionalismo en la narrativa de Osorio y a la luz del archivo personal del autor, esta desconfianza a las máquinas por su ausencia de espiritualidad le hará también rechazar las ideas propias de las vanguardias de principio de siglo. 
y económica: creían en la democracia, se mataban por ella, era la verdadera divinidad que había reemplazado todos los dioses de las doctrinas religiosas. Despertado un fanatismo unánime, era intocable y sagrada. (66)

No hay un modelo político a seguir. Al no creer en las capacidades -e incluso en la existencia misma- de lo político, la única alternativa es creer en una élite que gobierne racionalmente la nación. Pero como vemos, el Estado también tiene serios problemas que se podrían solucionar, no por medio de distintas aproximaciones a la teoría política del buen gobierno, sino por la búsqueda de la eficiencia. Son estas esperanzas de instituciones más eficientes las que harán que años después Osorio dirija sus intereses y alianzas no a instituciones de uno u otro lado del espectro político, sino a individuos que encarnan la esperanza de esa eficiencia y de esa solución. Estos individuos, si bien se ubicaron en diferentes puntos a lo largo del espectro, para Osorio todos poseían una capacidad casi mesiánica para llevar a cabo de manera rápida y eficaz profundos cambios sociales e institucionales en sus países. Será esto lo que le llevará primero a apoyar a Jorge Eliécer Gaitán, luego acercarse y trabajar para Juan Domingo Perón en Argentina, y por último para Rafael Leonidas Trujillo en República Dominicana. $\mathrm{Y}$ es por esto que, con la caída en desprestigio de estos personajes, bien fuera por un cambio en su relación personal con ellos o bien con lo que significaban, Osorio pasó frecuentemente de la esperanza a la decepción política. ${ }^{6}$

Esta hegemonía tajante de la élite sobre el pueblo es la proyección a un nivel social y político de la hegemonía clásica del espíritu sobre la materia, lo que nos permite ver la conexión entre sus ideales estéticos con los políticos. Como veíamos, la mecanización y la eficiencia han dejado perder la espiritualidad. Sin embargo, no es una pelea simple entre materia y espíritu. No todos los objetos o artefactos son malignos o despreciables, siempre y cuando los objetos tecnológicos no dejen la espiritualidad a un lado. En el caso de Barranquilla 2132 ese objeto es el avión, artefacto innovador y al mismo tiempo conductor hacia lo sublime. Los momentos en que Rogers se encuentra sobrevolando Barranquilla son los únicos que dejan la angustia y la incertidumbre de la alienación que vive en tierra para describir un sentimiento o sensación de éxtasis en el aire. El vuelo - posible por un aparato mecánico- no es sólo una maravilla tecnológica sino una posibilidad de experiencia mística o trascendental:

Pronto se encontró Rogers frente a la soledad formidable, a la serenidad magnífica del cielo, profundamente azul, sobre un mar intensamente verde. Sintió entonces una admiración casi mística: había logrado sustraerse a las preocupaciones cotidianas, a

6 Para el caso de la decepción con Gaitán, véase su biografía del líder político asesinado, Gaitán. Vida, muerte y permanente presencia (1952). Para el caso de su relación con la élite política colombiana, véase Vanderhuck. 
la reservación permanente de un sistema social exhorto, primitivo, imposible de ser penetrado por su facultad de acomodación. (84)

Uno de estos sobrevuelos desemboca en la persecución del causante de la explosión en el edificio donde se encontraba Rogers hibernando. Llegan al dirigible enemigo y se encuentran con que el material del que está hecho carece de bordes sólidos. Es una sustancia bituminosa que se abre y cierra según las órdenes del científico -el asfalto era una de las innovaciones más atractivas por esos años- permitiéndonos ver así los deseos de una materia que se pueda controlar a discreción del usuario. Al entrar al dirigible, Rogers se maravilla del interior, pues es una copia y un archivo, en términos de arquitectura y de contenidos que alberga la nave, de toda la belleza y la espiritualidad del siglo XIX y del siglo XX que para entonces se había perdido. Columnas romanas $\mathrm{y}$ arcos góticos hacen de soportes en el dirigible, $\mathrm{y}$ una colección de preciadas obras de arte a lo largo de todos los pasillos le hacen sentir que este científico encarna los ideales perdidos.

Pero volvamos al material del dirigible, porque es ahí donde vemos la intersección de materia y espíritu que Rogers tanto añora. Posiblemente debido a una comprensión parcial y precaria de los nuevos descubrimientos en el área de la física y las partículas por parte de Osorio, hay una curiosa mezcla entre idealismo filosófico y física nuclear. El material del dirigible, además de poder ser controlado por el científico, es materia pura y al mismo tiempo es el combustible de la nave misma: el dirigible "[...] no requiere combustibles, ni gases, ni nada. Se mueve por su propio impulso, por la propia sustancia de que está construido, la cual es insensible a las variaciones atmosféricas, al calor, al frío, al vacío mismo. Es la única posibilidad de emprender un viaje interplanetario" (93). Este es el gran adelanto de la ciencia llevada a cabo por este científico: la energía espiritual - ¿una posible interpretación vitalista de las posibilidades en ese entonces teóricas de la energía nuclear?- que impulsa un aparato mecánico. El material es la concreción en los imaginarios de la innovación de la idea del espíritu como energía de la materia, del alma como energía del cuerpo, y la élite política como energía o alma del pueblo.

Sin embargo, para grave consternación de Rogers, este supremo artífice del espíritu sobre la materia desea específicamente el control y dominio total del mundo al considerarse un dios, o al menos un superhombre:

[...] la fuerza cósmica es en mis manos maleable como el barro bajo los dedos del escultor. [Es por ello que lanza bombas desde su dirigible, porque hay que] sembrar la planta benéfica del terror. Que la humanidad comprenda la existencia de una fuerza omnipotente, superior a todas sus posibilidades de defensa, sujeta a la voluntad de un solo individuo, que hará su aparición oportuna, como un deus ex machina de la antigua comedia, ipara tomar posesión de mundo tembloroso y dócil! Ese individuo soy yo: yo, que impondré mis leyes, ipondré el mundo a mi servicio y haré que me 
adoren como a un dios y me erijan templos! La humanidad desfallece por la ausencia de un culto. $(100-101)$

Luego de muchas dudas Rogers liquida al científico, posiciona el dirigible en ruta hacia el Sol, y junto con el periodista salen en la avioneta para regresar a Barranquilla. Han eliminado la amenaza del científico, pero Rogers ha visto cómo su esperanza en la recuperación de los ideales antiguos de la belleza y la espiritualidad han sido cooptados por las ansias de poder de aquél. Es debido a ello, y no sólo debido a lo desconectado que se siente en esta época que Rogers, al final de la novela, decide dejar de ser parte de ese nuevo mundo.

2. Si en la novela de Osorio la innovación acarrea una pérdida trágica de la espiritualidad porque el presupuesto tácito es la de un poder político y social de la élite inamovibles, para Fuenmayor la disposición frente a la elite política es muy distinta. Aquí la innovación y lo nuevo no producen ansiedad. La llegada de lo nuevo -en este caso no se trata de un aparato o un artefacto, sino de un cúmulo de conocimientos y de la figura que los trae- se presta para entrar a burlarse de las elites que mantienen su hegemonía por medio de posturas autoritarias con el conocimiento. En este sentido, este pequeño texto que a duras penas contiene artefactos innovadores o noticias o especulaciones de adelantos técnicos, es una sátira dirigida no al político sino al "sabio" que practica lo que Héctor Rojas Herazo, otro autor caribeño, llamaría años más tarde "agiotismo intelectual" (198-199). Usando la tradición de la ciencia ficción, Fuenmayor transforma aquel "sabio", "letrado" en el "científico loco y maligno". La sátira que encontramos en este texto no es un ataque frontal, sino un sutil ejercicio de desarme de la autoridad del conocimiento por medio de la farsa, en la que el autor no perdona ni siquiera la figura misma del autor de textos.

La nouvelle de José Félix Fuenmayor comienza en un club social de la ciudad, probablemente Barranquilla, donde "[...] algunos caballeros se entregaban al deporte sentado del ojeo de noticias en los periódicos" (9). En este "saloncito de lectura del club" se discutía el asalto reciente de un sabio alemán recién llegado a la ciudad. Algunos sostienen que no importa cuán sabio parezca ser esta persona con todos sus conocimientos, pues sólo por el hecho de que se haya dejado asaltar indica que no es un sabio en absoluto. Otros en cambio opinan que es precisamente la incapacidad de entender la realidad prosaica, por estar alejado de ella -en este caso saber que no está corriendo peligro en un lugar- lo que le convierte en sabio. Las opiniones vienen y van, unos sugiriendo que los sabios deben estar conectados con el mundo diario, y otros que no.

El señor Currés, quien había estado en silencio, comienza entonces a leer en voz alta uno de sus relatos. A medida que progresa en la lectura sus escuchas se levantan para irse y otros entran a escuchar. Al finalizar esta pequeña historia, con la que acabará 
también el relato de Fuenmayor, el autor habrá sido el único en escucharla en su totalidad. Esto no será problema para muchos, pues no tienen problema en interrumpir a Currés y opinar sobre la historia. El autor nunca responde a estas opiniones. Sólo sonríe en silencio y prosigue con la lectura.

El relato de Currés cuenta la historia de catorce sabios que un día se montan en una "gigantesca máquina voladora" en "el aeródromo de una ciudad ilustre" para ir a hacer investigaciones a un lugar no especificado (15). Nunca se nos dice de dónde son estos sabios o a dónde viajan. Lo único que nos ayuda en la ubicación temporal del relato es que todos viajan junto con esposas e hijas en una avioneta. Esto nos permite empezar a creer que estamos frente a un relato de carácter científico, tal vez inspirado por Héctor Servadac de Jules Verne (1877): el astrónomo director de la expedición se llama Aldebrán, y viaja con "[...] doña Dalila, anciana mujer de Aldebrán; la señorita Leila, hija única, viripotente, del físico Polipasto y Zitita, nieta impúber del geólogo Colophon". La única excepción es el del piloto que, en contraste con estos nombres típicos de un drama o sátira francesa del siglo XVIII -o de muchas obras de Verne- se llama Cabrillitas. Pero no podremos seguir pensándolo.

En medio del vuelo, algo sorpresivo ocurre. No se sabe si es una tormenta o un rayo solar que golpea la tierra. Aterrizan de prisa y se dan cuenta que están en una tierra de rocas gigantes. Después de varias discusiones acerca de los principios metafísicos de la verdad, Aldebrán declara que un rayo cósmico golpeó la tierra causando su crecimiento repentino. Puesto que ellos no estaban en contacto con la tierra, ellos no crecieron, de modo que para efectos prácticos son diminutos seres en la arena. Sin pruebas ni método científico, ni tampoco uno de simple ensayo y error, y sólo a través de una voz autoritaria, se decide que esto es la verdad y no hay más discusión. Pasan entonces a mejorar y adaptar una cueva que encuentran y así poder vivir todos, creando una comunidad. Mientras tanto Aldebrán se dedica a entrar en contacto con los humanos ahora gigantes. Se encierra en su propia habitación -esto es lo primero que se construyey el resto del relato no es más que los ires y venires de las rencillas entre sabios, con especulaciones pseudocientíficas aquí y allá. Pronto percibimos que en el fondo de todas estas especulaciones yacen, simplemente, las pugnas sentimentales porque unos desean las hijas de los otros. Muy pronto, sin que Aldebrán logre comunicarse con los humanos gigantes, las discusiones, impulsadas por celos y deseos, llevan a que todos estos sabios se maten mutuamente. Después de la muerte masiva de todos, Aldebrán sale de su habitación, se sorprende, y al subir las escaleras para salir al mundo exterior se cae, y golpeándose la cabeza muere también.

Entrada la noche, el saloncito de lectura guarda silencio después de terminada la historia. Nadie dice nada; el autor del relato tampoco, pues se da cuenta que está tarde y sale corriendo para su casa, porque su esposa lo recriminará por su falta de puntualidad.

Desde los parámetros del realismo, parámetros que en general los romances científicos de Wells y las novelas de Verne tienden a respetar, esta nouvelle no es una obra bien 
lograda. Pero esto no se debe a deficiencias en su elaboración. Hay que prestar atención al aspecto satírico y al trasfondo platónico en la estructura y en la aproximación a los eventos. La primera línea del texto denota ya el distanciamiento propio de la sátira. Esto es un saloncito de lectura, donde se practica el deporte del ojeo de noticias. No es una conversación seria ni rigurosa. Es tan sólo un recuento, un ir y venir de opiniones. Los personajes de esta escena de lectura no tienen gran profundidad y complejidad psicológica; sólo son escuchas, oídos atentos a la historia. Los personajes del relato del señor Currés tampoco son bien logrados en un sentido realista de la clasificación.

En esta ágora de ciudadanos acomodados, ciudadanos que al leer y comentar las noticias no hacen más sino practicar la sofística, un texto entra a intervenir en el debate. Un texto lleno de personajes que encarnan cada uno una idea, personajes que funcionan como emblema y no tanto como personajes en el sentido de la prescriptiva literaria realista del siglo XIX y del XX. Más aun, este texto, al igual que el famoso diálogo de Platón, gira alrededor de una caverna. Pero aquí las semejanzas con Platón se detienen, o mejor, se invierten. Porque si la alegoría de la caverna se refiere a la adquisición de las verdades trascendentales y eternas por encima de las verdades cotidianas y manipuladas propias de los sofistas, aquí lo que tenemos es un retorno a la caverna. La mayoría de los personajes son sabios, varios de ellos filósofos, interesados en ideas trascendentales, eternas y absolutas, pero al descender a la cueva descienden también al nivel de las disputas prosaicas surgidas a partir de los celos y de la atracción sexual, de las envidias personales, y las conspiraciones para lograr propósitos en común.

Por otro lado estos sabios, si bien hablan de ciencia, no son propiamente científicos. Nunca los vemos hacer un experimento, o utilizar racionamientos rigurosos o el método científico para plantear una hipótesis. Es más, sus hipótesis siempre las consideran como la verdad absoluta -no son por ello propiamente hipótesis-, y muchas de ellas son aseveraciones propias de la metafísica y no del mundo que en rigor le concierne a la ciencia. Estos sabios son solamente personas que opinan, al igual que los escuchas en el salón de lectura del club. La descripción del filósofo Dormón en el relato del señor Currés funciona perfectamente para describir las opiniones de todos los sabios, pero también las de los escuchas en el club: "[...] pariendo de los criaderos de sus circunvoluciones cerebrales salían frecuentemente por sus labios serenas estructuras ideológicas, como seres vivos que en la boca del sabio iban rompiendo el cascarón de la palabra y enseguida emprendían vuelo hacia desconocidos lugares del espacio" (28-29). Las ideas simplemente fluyen, salen de la boca de las personas sin rumbo fijo, sin ninguna utilidad. No hay instrumentalidad en los razonamientos de los sabios, así como tampoco la hay en las opiniones de los oyentes del señor Currés. La diferencia, claro está, radica en la distinción cultural e intelectual de personajes y oyentes, entre sabios y no sabios.

Al principio del relato de Fuenmayor, cuando se hablaba del asalto al científico alemán, se hacía una diferencia entre conocimiento práctico - el conocimiento conectado a la 
industria del comercio, el conocimiento del ingeniero y del empresario-y el conocimiento distante del comercio pero de mayor estatus en sociedades más tradicionales, conectado al concepto de "sabiduría" -el conocimiento del sacerdote, del abogado, del médico, o del maestro-. Hay un contraste presente aquí a distintos niveles: un conocimiento socialmente importante para un mundo rural y decimonónico latinoamericano, en oposición a un conocimiento urbano, más propio de la Barranquilla de ese entonces, que tiene rápidas aplicaciones especializadas. En otro nivel es también el conocimiento proveniente del extranjero en contraste con el local.

Además, esta discusión tiene lugar en Barranquilla, y como hemos visto en el caso de Osorio, esta es una ciudad portuaria que no es la capital política del país pero que durante los años veinte y treinta se convierte en la capital económica y cultural de la nación. Es por ello que no debemos olvidar las diferencias entre regiones. Las formas del conocimiento son aquí planteadas en una relación disyuntiva entre el poder social, cultural y político (tradicional) del centro andino con sede en Bogotá -el de los sabios gramáticos, abogados y humanistas-y la nueva clase empresarial, técnica, especializada, que empieza a aparecer en el Caribe. Sin que esto sea dicho en el texto de Fuenmayor, fácilmente podemos imaginarnos el saloncito de lectura del club como un sitio de encuentro entre personas de estas dos posiciones sociales, cada una con perspectivas muy distintas acerca del lugar y la función del conocimiento en la sociedad, en la cultura y en el funcionamiento del Estado. Sin duda se encuentran presentes médicos y abogados, pero también ingenieros.

Si éstas son las disyuntivas presentes en el texto, faltaría entonces encontrar cuál es la postura del autor. Sería fácil, si nos enfocáramos en las diferencias entre costa caribe y centro andino, dictaminar que Fuenmayor, oriundo de Barranquilla, está simplemente burlándose de los "cachacos", los habitantes de Bogotá: aquellos sabios gramáticos del centro (Miguel Antonio Caro, Rufino José Cuervo, entre otros), estandartes de la hegemonía conservadora que estaba a punto de terminar, pareciera decirnos Fuenmayor, juzgan apresuradamente la nueva realidad. Pero si nos enfocamos en la relación entre local y global, parecería entonces que Fuenmayor, como buen arielista, estaría criticando la llegada de la industrialización y de la modernización, a través de las falacias de las posturas cientificistas. O simplemente, se podría decir que Fuenmayor es un típico escéptico, pensando que aquel sabio alemán víctima de un robo es tan sólo una muestra de que todo ese conocimiento no sirve en una realidad como la local.

Pero tengamos en cuenta la construcción del relato, en particular el descenso a la caverna por parte de unos sabios que en verdad no lo son. Recordemos que Aldebrán se impone sobre los otros a partir de una voz de autoridad, y no por medio de un método deductivo o inductivo. Cuando discuten qué es lo que deben hacer, el biólogo Peritón lo desafía a un duelo a muerte. Aldebrán entonces declara, en lo que parecería ser una crítica al poder de la élite del siglo XIX no sólo bogotana sino también cartagenera - 
ciudad portuaria pero mucho más colonial y tradicional, incluso hoy en día- que también podría ser una reflexión sobre la violencia en el país de esa época:

[...] la palabra combate - dijo Aldebrán- alucina y atrae con su brillo sangriento. Con ella suele aparearse en la mente lo maravilloso heroico de la epopeya. ¿No es verdad, Peritón, que cuando dijiste llamo el combate varonilmente, ya te sentías grande y digno de honor y de alabanzas?... Te engañan, Peritón, las loas cantadas por la Historia a las acciones guerreras; $y$ no descubres que estas son desfiguradas por la protervia, el vano orgullo y la incomprensión de los humanos; por los comentarios del falso o verdadero patriotismo donde esconden la garra los conquistadores y por los diabólicos arreos de la poesía delirante. (34)

En esta escena burlesca y satírica, donde los sabios para probar una supuesta hipótesis deben recurrir al duelo, Aldebrán revela el centro de la discusión de Fuenmayor, donde la crítica y la ufana muestra de conocimiento no es una búsqueda de verdad sino una búsqueda de posicionamiento frente a los otros. Es mostrar quién es más fuerte y quién tiene más poder. Esto se ve más claramente cuando el sabio Hamat revela ser en verdad un mago negro que quiere la sangre de todos para ser todopoderoso, asesinando a la mayoría de los habitantes de la caverna (56).

Detrás del científico sabio, lo que hay según Fuenmayor es un brujo, un encantador con ansias de poder. En la historia tradicional del género gótico y de la ciencia ficción, podemos rastrear la conversión de este mago maligno en científico loco, desde Fausto hasta los antagonistas billonarios de James Bond que quieren acabar o dominar el mundo (Nelson, capítulo I). Se podría entonces argüir que Fuenmayor en este caso sólo repite los tropos convencionales de la sospecha surgida de lo nuevo, algo típico en novelas como Frankenstein, o en el período escéptico y melancólico de los comienzos de la obra de Verne. ${ }^{7}$ Sin embargo, a un nivel nacional, la imagen del mago Hamat no está lejos de la imagen del sacerdote, propuesta por la crítica liberal de la época, como alguien tradicional y despiadadamente poderoso. Esta burla o sátira de la ciencia no estaría entonces dirigida a la práctica científica como tal, ni dirigida hacia el progreso-en ningún lugar se hace evidente que se busque permanecer en un estado premodernizado o no industrializado-. Tampoco es una crítica hecha desde un punto de vista existencialista y angustiado como el que veremos en la novela de Osorio Lizarazo.

La crítica y la posición de Fuenmayor yace en un lugar ecléctico y cínico -en el sentido clásico de estas escuelas filosóficas de la Grecia Antigua-. La burla del poder científico no es aquí una lucha entre norte y sur como lo había planteado Martí en

Véase El maestro Zacarías (1854) y en especial París en el siglo XX (1863), novela que su editor PierreJules Hetzel decidió no publicar al considerarla demasiado pesimista. Hubo que esperar hasta 1994 para que esto ocurriera. 
Nuestra América o, bajo otras coordenadas, Rodó en Ariel décadas antes. La burla del poder científico, o mejor, la burla del poder del conocimiento sobre la sociedad, es una burla que no busca poner el mundo al revés; no es una burla carnavalizante ni mucho menos. Es una burla, típica de la Costa Caribe colombiana y hecha famosa por García Márquez con la expresión "mamadera de gallo": es la introducción de una burla o de un rizo humorístico en una situación para desactivar la urgencia o la gravedad de éste.

Esto no quiere decir que el discurso científico pase sin mácula. El sexo, el poder y la vanidad yacen en el centro de los discursos científicos y racionalistas. En este sentido, las elucubraciones de Jules Verne o de H. G. Wells, textos que probablemente conocía Fuenmayor, también pasan a ser objetos de esta burla.

El texto de Fuenmayor no es una crítica al conocimiento científico modernizante, ni una crítica de los valores tradicionales del pasado. Es un texto de una risa igualizante. El alemán que llega a Barranquilla es un sabio, pero Fuenmayor le quita todo poder. Lo mismo hace Currés al quitarle todo poder a los catorce sabios. E incluso él mismo carece de autoridad, pues tiene que responder a su mujer y no quedarse a recibir la gloria de los escuchas. El texto mismo evita cualquier asomo de autoritarismo al no plantear ninguna posición contundente. La risa igualizante, no carnavalizante, hace precisamente que todos, los sabios tradicionales bogotanos y costeños, decimonónicos y contemporáneos, cercanos a la industria o separados de ella, europeos o colombianos, todos sean exactamente iguales: simples personas que pueden ser objeto de risa porque lo único que disfraza el conocimiento son los deseos, las envidias y las pasiones sexuales. Y es aquí donde yace la igualdad entre personas de regiones, países, clases y posiciones.

3. A diferencia de Fuenmayor y Osorio, quienes son reconocidos en la historia literaria colombiana como escritores de literatura más canónica, Manuel Francisco Sliger Vergara es el único de estos tres escritores que no se dedicó a la literatura. Su novela Viajes interplanetarios en zepelines que tendrán lugar en el año 2009 es la única obra que publicó. Poco más sabemos de él. Sólo que nació en Montería, ciudad en el sur del Caribe colombiano, y que al ser hijo de padre norteamericano, combatió para los Estados Unidos durante la Primera Guerra Mundial (Sliger), y que murió en Cincinnati en la década de los ochenta. Sólo podemos entonces hacer especulaciones acerca de las influencias y bagaje cultural del autor a partir de ciertas señas que encontramos en la novela. Pero algo podemos decir de entrada, y es que la novela revela claramente que Sliger no estaba interesado en el mundo literario, ni en la literatura propiamente dicha. Era un escritor interesado en la visualidad, y eso, más allá de la factura de su novela, es el particular aporte que hace a la confrontación con lo nuevo.

De las tres novelas, esta es la que más se ciñe a los principios establecidos en Estados Unidos por Hugo Gernshank en Amazing Stories en 1926. En esta revista se publicaban artículos de divulgación científica junto con textos de ficción, los cuales, 
según el editor, también estaban obligados a dar a conocer las nuevas tecnologías. Esto hacía que la narración se debiera interrumpir repetidas veces para exponer y describir minuciosamente los adelantos técnicos o científicos que aparecían en la historia. Esta prescriptiva de "la fórmula Gernsback" marcaría la literatura de ciencia ficción en revistas de tiraje masivo durante décadas. La novela de Sliger se ciñe a esta manera de contar la historia, haciendo pausas constantes para exponer las nuevas tecnologías.

En la novela encontramos una estructura casi episódica de los eventos, como si la novela hubiera sido pensada para una publicación seriada, aunque no hay indicios de que esto hubiera sido el caso. Esta estructura y estos eventos son seguramente inspirados por las novelas por entregas como las del ciclo Barsoom de Edgar Rice Burroughs (publicadas a partir de 1911 en inglés). Esta influencia, sumada a la poca profundidad psicológica de los personajes, podría para ojos más tradicionales verse como una falta de apropiación de la cultura literaria del momento. En efecto, según los cánones del realismo y de la literatura "seria" o "adulta", esta novela sería sólo para tirar a la basura: no sólo es de un género menor como el de ciencia ficción, sino que los personajes aparecen acartonados, sin dimensiones psicológicas interesantes ni complejas. A su vez, el argumento no podría ser más prosaico. El viaje accidentado de Tómas, un policía interestelar, a través del Sistema Solar para llegar al final a una relación estable con una mujer miembro de la clase gobernante de Marte. Hay en la novela serios errores en términos de repeticiones, de puntos de vista de los narradores e hilos argumentativos que se dejan sin terminar. Asimismo, encontramos frecuentes errores en la selección de vocabulario y en el uso de registros formales e informales.

La novela además, cambia de sub-género narrativo varias veces: pasa de ser una novela de feria al principio, como la novela del mismo Gernsback Ralph 124C 41+ (1911), en la cual un paseo por una feria en el futuro permite ir exponiendo una gran cantidad de inventos; luego es una novela de exploración del Sistema Solar, pero con grandes influencias de la novela de viajes marítimos (en un momento, en medio del espacio, se abre una exclusa y se tira un balde de residuos); luego pasa a ser una novela de contacto con civilizaciones primitivas, las cuales viven en los asteroides entre Marte y Júpiter, y de inmediato se convierte en una novela de intriga de palacio, cuando Tómas llega a Marte a conocer la familia de su novia Josefina. Después de sufrir el amor no permitido por la madre de su novia, parten a luchar en la guerra contra los misteriosos seres provenientes de Mercurio. Si bien estos aparecen al principio de la novela, sólo vuelven a aparecer en las últimas tres páginas del libro. Al final Tómas y Josefina derrotan a los mercurianos, para luego retirarse a un sitio aislado en la tierra a vivir juntos y crear una familia.

Cualquier lector consciente de las posibilidades retóricas de un lenguaje económico y bien escogido rechazaría de inmediato la novela. Es un hecho que un serio trabajo de edición reduciría las cuatrocientas páginas a menos de doscientas. Pero es en estos 
defectos de la lengua escrita donde se pueden percibir los síntomas de otras influencias que impulsan al autor a contar una historia como esta, aunque sin ofrecerle las herramientas más adecuadas para hacerlo de una manera efectiva en el género que ha escogido.

Y es que estos "defectos" narrativos son en verdad el testimonio de los rastros de una influencia no literaria sino visual. Podemos imaginar a Sliger leyendo tiras cómicas como The Yellow Kid en las trincheras de la Primera Guerra Mundial, y teniendo acceso a la literatura de consumo popular en lengua inglesa. ${ }^{8}$

Asimismo, las descripciones y la estructura episódica del argumento, en vez de verlas como simples muestras de mala escritura, pueden deberse también a la estructura episódica de cortometrajes y de personajes de la cultura popular que abundaban en la época, como por ejemplo The Shadow (aparece en 1930 en radio y en prensa en 1931), o Mandrake, the Magician (1934). Si las graves deficiencias bajo los cánones realistas de la profundidad y complejidad de personajes se juzgan desde el punto de vista de esta literatura gráfica, serializada y popular, se vería entonces que no simplemente es un fallo en la compenetración con una cultura literaria, sino la consecuente comprensión de una cultura gráfica popular y distinta a la literaria. Se podría entonces incluso decir que Sliger escribe una novela porque no se le ocurre escribir una tira cómica, o porque no hay canales adecuados para la publicación de algo por el estilo en ese momento, o tal vez -una respuesta más digna de Ángel Rama- porque la cultura letrada de un país como Colombia fuerza a un escritor en ciernes a dejar de lado la posibilidad de escribir relatos de ciencia ficción como los publicados por Gernsback, para tratar de incluir en su relato los tropos narrativos más comunes de la novela de la época. ${ }^{9}$ En este caso, si bien Sliger podría estar impulsado por ansias de poder en el campo literario porque no conoce ninguna otra forma de verse como escritor, no usa las estrategias ni las herramientas del letrado. Sliger es tal vez el primer caso en Colombia de un autor que no ve la cultura letrada sino la cultura visual como el fundamento de su formación y de su visión de mundo. Si hubiera tenido los medios y encontrado un entorno apropiado, lo más probable es que Sliger no hubiera escrito un libro sino dirigido cortometrajes o dibujado historietas.

Hay múltiples instancias de estos usos de lo visual en la novela, demasiados para analizarlos todos en este espacio. Sin embargo, hay una que es primordial para la comprensión de la factura de esta novela, tanto de sus errores como de sus aciertos. La preponderancia de lo visual es tan clara en el texto porque la misma comprensión

8 Al ser bilingüe, algo muy poco habitual en la Colombia de la época, también explicaría la dificultad de comprender y manejar registros formales e informales correctamente.

9 La intriga de palacio en Marte, por ejemplo, es seguida por una fuga de Tómas y Josefina hacia una guerra incierta en el espacio exterior, adoptando la narrativa de La vorágine (1924), un gran éxito comercial y de crítica en la época. 
de los procesos mentales es concebida en función de preconcepciones visuales y no lingüísticas. ${ }^{10}$

El primer caso es la "reveladora", un aparato que no sólo lee los recuerdos sino también el futuro de una persona. El inventor se halla en la feria y le explica a Tómas cómo funciona a medida que lo prepara para el aparato. Aquí vemos, aparte de la mencionada falta de atención en la escritura misma, una curiosa mezcla de ideas cartesianas sobre el lugar del alma en el cerebro junto con ideas de impresión de memorias en el papel fotográfico:

En resumen -dijo- la idea se concentra sobre esa sección que los fisiólogos llaman el encéfalo y lo que es más, penetrando aún hasta lo más interno del mismo encéfalo, llegamos a una masa sensual llamada el centro de los sentidos, en el cual se encuentra el asiento del alma, donde tienen lugar los sueños. En él se incita el instinto, o sea ese sexto sentido del ser humano. Parece que lo que el individuo ha visto, o experimentado está inscrito en la memoria, en la misma forma que el rollo de una película, pues es retenido en la fisura longitudinal que se encuentra del lado derecho; mientras que el futuro se halla inscrito en el rollo que está en las circunvoluciones de los hemisferios, formando allí, pues, el asiento de la memoria. Así es que todos estos rollos, que comprenden escenas, fisuras, etc., son reflejados al través de la pupila y desplegados después por el nervio óptico del cerebro. [...] La fotografía de lo que el cerebro ve es proyectada contra el diafragma y ampliada cuya ampliación [sic] es después conducida a una pantalla. (50-51)

Esta máquina no sólo nos revela una no muy clara comprensión de Descartes, sino también una llevada al extremo de la mecanización de los procesos mentales en términos de la invención fotográfica. Esta no es la primera ni única vez que pasa, pues vemos el mismo fenómeno de uso de tecnologías para explicar aspectos en ese entonces no todavía comprendidos de la naturaleza humana (los autómatas en "El hombre de arena" de E.T.A. Hoffmann o la electricidad en Frankenstein de Mary Shelley, por ejemplo). Pero lo interesante aquí es que, a diferencia de la importancia que la alta cultura impone sobre la palabra - desde la Biblia, hasta la deconstrucción y la filosofía del lenguajeaquí vemos una traducción directa de procesos mentales a imágenes fotográficas sin pasar por la lengua.

Otro invento hace aparición cuando Tómas se encuentra en el palacio marciano de los padres de Josefina, y nos revela la posición que la letra tiene en el proceso de modernización para Sliger. La "máquina-libro" lee los libros y automáticamente los adapta para un entorno visual:

${ }^{10}$ Esto no es nuevo. Para un estudio ejemplar de las influencias de lo visual en Kant y Hegel, véase Andriopoulos. 
La Máquina-Libro no era sino en realidad un carretel de un alambre de acero, sumamente fino, el cual pasaba al través de una máquina hecha con el fin de hablar, al estilo del fonógrafo nuestro y refería la historia en voces adecuadas a los caracteres diferentes representados en la novela o libro en cuestión. Uno también podía, si quisiese, apretar un botón que quedaba al lado de la máquina y ponía en movimiento películas que actuaban sincrónicamente con la historia narrada, contribuyendo así a la veracidad del libro. (239)

Si bien la primera parte de la cita es algo que ya conocemos, como los programas de lectura automática, la última oración es lo más interesante: aquí no hay cuestionamiento alguno del proceso de adaptación de un texto a imágenes. La máquina convierte la palabra en imagen sin preguntar todos los detalles que un guionista se debe preguntar al hacerlo. Por supuesto, no hay reflexión alguna, por ejemplo, sobre el sonido en la película con excepción de las voces de los personajes.

Este invento parece también una simple comprensión superficial de lo que implica leer y luego adaptar a un entorno visual en tanto a procesos cognitivos. Pero debajo de esa superficialidad yace la poca importancia que tiene la palabra. Para Sliger ella no es el vehículo de transmisión de nuevos conocimientos, y por ello del desarrollo de la modernidad, sino un aspecto más del mundo que la tecnología logrará superar. Sliger es un escritor que no valora la palabra escrita, pero que tampoco está interesado en entrar en conflicto con ella y con quienes la enarbolan como importante pues es algo que tarde o temprano se dejará a un lado. Es por eso que podemos argüir que si hubiera habido una industria fílmica o de tiras cómicas en el país, Sliger no habría tal vez escrito esta novela.

Es aquí donde yace la aproximación a lo nuevo en Sliger. Si bien es la novela más desigual, es la más radical en sus aproximaciones, pues plantea sin quererlo no un cuestionamiento de los modelos políticos de las élites (Osorio), o una burla de sus usos del conocimiento (Fuenmayor), sino dejar completamente a un lado la palabra y la escritura, el mecanismo por excelencia de preservación y conservación de poder en la sociedad colombiana.

Más allá de la maravilla tecnológica que hace posible el desplazamiento aéreo, y el consecuente acortamiento de tiempo al recorrer distancias, el vuelo y la posibilidad de hacerlo repercuten en las economías significativas de las tres novelas. No como simples alegorías o emblemas de un deseo de innovación, sino como un desarrollo en el punto de vista desde los cuales se interpretan y comprenden los fenómenos sociales y culturales (Osorio), como un elemento contingente que sólo es una excusa para examinar la relación entre ciencia y autoridad (Fuenmayor), y como un mecanismo de desplazamiento a nivel mental de los valores tradicionales de lo escrito (donde la rapidez del transporte se convierte en un imperativo que llega a abarcar la lectura y la visualidad (Sliger). La relación que estos tres autores tienen con lo nuevo no es la de una confrontación directa, o de una defensa ciega; es una de aproximación sutil del fenómeno, desde diferentes puntos y alturas. Son sobrevuelos exploratorios de algo que 
apenas comienzan a entender, a juzgar y a proyectar como parte del futuro, tanto de sus mundos ficticios como de los suyos propios.

\section{BiBLIOGRAFÍA}

Andriopoulos, Stefan. Ghostly Apparitions: German Idealism, the Gothic Novel, and Optical Media. Nueva York: Zone Books, 2013.

Calvo Isaza, Óscar Iván. "Literatura y nacionalismo: la novela colombiana de J. A. Osorio Lizarazo". Anuario colombiano de historia social y de la cultura XXXVI/2 (2009): 91-119.

Csicsery-Ronay, Jr., I. "Marxist Theory and Science Fiction." Cambridge Companion to Science Fiction. E. James y F. Mendlesohn, eds. Cambridge: Cambridge UP, 2003.

Fuenmayor, José F. Una triste aventura de 14 sabios. Bogotá: Laguna Libros, 2011.

Jameson, Fredric. Una modernidad singular. Ensayo sobre la ontología del presente. Barcelona: Gedisa, 2004.

Mouffe, Chantal. En torno a lo político. Buenos Aires: Fondo de Cultura Económica, 2007.

Nelson, Victoria. The Secret Life of Puppets. Cambridge: Harvard UP, 2001.

Osorio Lizarazo, José Antonio. Barranquilla 2132. Bogotá: Laguna Libros, 2011.

Rojas Herazo, Héctor. La magnitud de la ofrenda. Medellín: Fondo Editorial Universidad EAFIT, 2003.

Scheuerman, William E. "Globalization." The Stanford Encyclopedia of Philosophy. Edward N. Zalta, ed. Stanford: Methaphysics Research Lab. Stanford U, 2010.

Sliger, Manuel F. Viajes interplanetarios en zepelines que tendrán lugar el año 2009. Bogotá: Laguna Libros, 2011.

Suvin, Darko. Metamorphoses of Science Fiction. On the Poetics and History of a Literary Genre. New Haven: Yale UP, 1979.

Vanderhuck Arias, Felipe. La literatura como oficio: José Antonio Osorio Lizarazo 1930-1946. Medellín: La Carreta Editores, 2012. 
